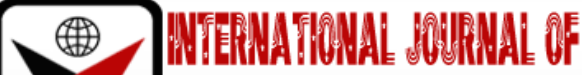 \\ בmRक
}

ISSN 2278-0211 (Online)

\section{Risk Assessment of Covid-19 Infection among Healthcare Workers at 3 Treatment Centres in Katsina State, Nigeria}

\begin{tabular}{c} 
Dr. Medinat Suleiman Ronke \\
Consultant, Department of Medical Microbiology, Federal Medical Centre, Katsina, Nigeria \\
Dr. Joan Ejembi \\
Consultant, Department of Medical Microbiology and Parasitology, \\
Ahmadu Bello University Teaching Hospital, Zaria, Nigeria \\
Dr. Halima Haladu \\
Dr. Taiwo Wulemot Oloyode \\
Consultant, Department of Chemical Pathology, Federal Medical Centre, Katsina, Nigeria \\
Consultant, Department of Chemical Pathology, Federal Medical Centre, Katsina, Nigeria \\
Dr. Jemila Suleiman \\
Consultant, Department of Haemotology, Federal Medical Centre,Katsina, Nigeria \\
Dr. Raliya Aliyu \\
Consultant, Department of Internal Medicine, Federal Medical Centre, Katsina, Nigeria \\
Dr. Abdullahi Sanda \\
Consultant, Department of Medical Microbiology, Federal Medical Centre, Katsina, Nigeria \\
Dr. Yohanna Joseph \\
Consultant, Department of Otorhinolaryngology, Federal Medical Centre, Katsina, Nigeria \\
Dr. Abdulmajeed Suleiman \\
Consultant, Department of Otorhinolaryngology, Federal Medical Centre, Katsina, Nigeria \\
\hline
\end{tabular}

\section{Abstract:}

The Coronavirus disease 19 (Covid-19) has gradually spread all over the world becoming a serious public health problem. The pandemic has virtually affected the economic systems of both the developing and developed world. Health workers are the front-liners of the covid-19 outbreak and are exposed to hazards that put them at risk of the infection. The major reason for health care workers infection is their lack of understanding of the disease, unavailability of personal protective equipment's (PPEs), psychological stress to mention but few.

The aim of the study is to assess the exposure of healthcare workers to covid-19 and to improve Infection, prevention and control (IPC) practices at all level and contain the current covid-19 outbreak at Federal Medical Centre Katsina, Turai Maternal and Child Health and General AmadiRimi Specialist Hospital.

There were 28 positive cases and 56 controls in ratio 2:1. Males were 63 while females were 15. The mean age was 36. Doctors were mostly affected. Those adequately trained for covid-19 IPC were 47\%. Those who knew what risk assessment was 23\%. Health Care Workers with community exposure were $60.3 \%$ and those with occupational exposure were $35.9 \%$. High risk group in this study were use of $N 95$ or its equivalent (54\%), removal of PPE according to protocol (71\%), hand hygiene after touching patients surrounding (58\%). Decontamination of high surfaces (74\%). Protection of health care workers should be made a priority by regularly training and retraining them, making PPES available, ensuring HCWs get tested.

Keywords: Covid-19, Health Care Workers, IPC, PPE, Katsina, Nigeria

\section{Introduction}

Thousands of health workers globally have been reported to be infected with the coronavirus caused by severe acute respiratory syndrome coronavirus (SARS-COV-2)ithe pandemic has challenged the health systems of most countries. It has affected no more than 11 million people with about 528,364 deaths and over 6 million recoveries in 187 countries as of $5^{\text {th }}$ July $2020^{\text {ii. }}$. The person-to-person transmission routes of covid-19 includes direct transmissions, such as cough, sneeze, droplet inhalation, transmission, and contact transmission, such as the contact with oral, nasal and eye mucous membranesiii.

Health workers are the front-liners of the Covid-19 outbreak response and are exposed to hazards that put them at risk of infectioniv.

In Nigeria, about 812 healthcare workers are infected 29 of these people work for NCDCv. 
Frontline health workers could be at high risk of infection because of close contact with an infected patient. HCWs with infection could cause secondary transmission among patients, family and the community. Hence, it is essential to investigate the infection risk of healthcare workers.

Therefore, it is a public health priority for policymakers to be aware of the vulnerable group's risk factors to prevent occupational transmission.

It is highly contagious. Its high transmissibility has resulted in many infections and hospitalization, even among health care workers. They are at risk of acquiring covid-19 due to increased occupational exposure to SARS-COV-2.

Insufficient access to personal protective equipment (PPEs) or weak infection prevention and control measures raise the risk of health workers infection; health workers can also be exposed to an asymptomatic patient in the health facility for a range of other services. The risk may also arise when health personnel repurpose for a covid-19 response without adequate breathing or a heavy workload, resulting in fatigue worn-out and possibly not entirely using the standard operating procedures. In most African countries, infection, prevention and control measures aimed at preventing infections in health facilities are still not fully implemented ${ }^{\text {vi. }}$

In late July 2020, the World health organization announced that over 10,000 healthcare workers in Africa had tested positive for covid-19vii. Only 16\% of about 3000 facilities surveyed by WHO has assessment scores above $75 \%$. Most healthcare centres do not have the infrastructure necessary to implement key infection, prevention measure or to avoid congestion. Only 7.8\% (2213) had isolation facilities, and just one third could triage patient. 10\% of covid-19 in SerriaLeone were among health workers, which has dropped to $9 \%$ in Cote d'Ivoire. The infection among health workers has dropped from $6.1 \%$ to $1.4 \%$, scaling up IPC measures can further reduce infections among health workers.

WHO defines health workers as all people engaged in action whose primary intent is to enhance health: this includes doctors, nurses, midwives, paramedical staff, hospital administrators and support staff, and community workers who are at risk of infection with Covid-19 protecting HCW is challenging.

In most countries, where there is inadequate PPE, limited testing capacity produces early identification and isolation cases. But HCW is mostly at risk because the majority of patient with Covid-19 remain asymptomatic. Unmitigated, rising infection and mortality rates in Healthcare Workers paralyses a country response to Covid-19viii. It is bound to have a significant long-term impact on the country's health care delivery. There is a shortage of HCW due to skilled labour migration and geographical mal-distribution even before the pandemic.

\subsection{Aims}

To assess the exposure of Healthcare workers to covid-19 and to improve Infection, prevention and control (IPC) practices at all level and contain the current covid-19 outbreak at Federal Medical Centre Katsina, Turai Maternal and Child Health and General AmadiRimi Specialist Hospital.

\subsection{Objectives}

- To assess and compare exposure among infected and non-infected HCWs who managed COVID-19 patients at Federal Medical Centre Katsina and the two other hospitals.

- To identify gaps in IPC practices among HCWs at Federal Medical Centre Katsina and the other two hospitals.

- To explore infection risk and discuss possible prevention measures.

\section{Methods}

\subsection{Study Area}

We conducted the operational research at three treatment centres. These were Federal Medical Centre Katsina, Turai Maternity and Child Centre and General AmadiRimi Specialist Hospital Katsina (G A R S H). Federal Medical Centre Katsina is one of the Treatment Centers for COVID-19 in Katsina, Nigeria.

\subsection{Study Design}

An unmatched case-control study at the ratio of 1:2 was conducted at this treatment facility. Screening of health care workers began with symptomatic ones and those that have contact with covid-19patients. Testing for covid-19 was done using a deep nasopharyngeal swab by trained professionals; validated RT-PCR was performed at the reference lab to confirm infection.

A case was defined as HCW irrespective of cadre who tested positive for SARS CoV-2 by PCR after exposure to confirmed cases of COVID-19. In contrast, controls will be defined as HCW who tested negative for SARS CoV-2 by PCR after exposure or contact with confirmed cases of COVID-19.

For every SARS CoV-2 positive HCW, two controls who had contact with the index cases were selected, and the risk assessment of both cases and controls conducted.

\subsection{Study Population}

All cadre of HCWs at Federal Medical Centre Katsina, Turai Maternal and Child Hospital katsina, General AmadiRimi Specialist Hospital Katsina (GARSH), who tested positive to SARS CoV-2 were selected as cases and controls were all cadres of HCWs at Federal Medical Centre Katsina and the two other hospitals, who tested negative to SARS CoV2 . 


\subsubsection{Inclusion Criteria}

All healthcare workers (doctors, nurses, scientist, pharmacist, attendants, cleaners) at FMC Katsina, Turai Maternal and Child Hospital and General AmadiRimi Specialist Hospital.

\subsubsection{Exclusion Criteria}

Non-healthcare workers.

\subsection{Study Measures}

Community exposure to covid-19 was assessed using the WHO risk assessment tool, part one of the tools. Respondents are community exposed if they answer 'yes' to a history of staying in the same household or classroom with a confirmed Covid-19patient. Travel history in close proximity (within one meter) with a confirmed covid-19 patient.

Occupational exposure; This is assessed if healthcare workers respond 'yes' to section 4 of the WHO assessment tool; these provide direct care to a confirmedCovid-19patient. Performing aerosol-generating procedures on confirmed covid-19 patient and had direct contact with the patient environment.

Risk categorization of health care workers exposed to covid-19. Health workers are considered high risk if their response is no to 'always as recommended' options to WHO HCWs risk assessment tool and low risk if their response is 'yes' to other options to the following IPC measures; wearing of single used gloves. Medicalmask, face shield or goggles, disposable gown, removing and replacing PPE according to protocol, performing five moments of hand hygiene, aerosolgenerating procedures, decontaminating high touch surfaces at least three times daily, and any accident with body fluid/respiratoryix.

\subsection{Data Collection Tools}

This study utilized quantitative and qualitative data collection methods were.

The WHO adopted a risk assessment tool and a structured interviewer/self-administered questionnaire with closed and open-ended questions using the quantitative method. This questionnaire had sections on demography, index patients, exposure, IPC knowledge and practicex.

Did a qualitative method via Focus group discussion (FGD) conducted among Cases and Controls using an FGD guide.

\subsection{Ethical Consideration}

- Consent: Obtained Verbal and written consent from all participants. Participation was voluntary, and participants were allowed to withdraw at any point during the study.

- Ethical approval: Sought ethical approval from the Federal Medical Centre Katsina Ethical committee.

- Data analysis: Data was analyzed using SPSS version 21

\section{Result}

Federal Medical Centre was the primary treatment centre with the highest number of positive cases. 22 Health care workers tested positive for covid-19within six months. Turai Child and Maternity hospital Katsina had three health care workers that tested positive, but 2HCWs volunteered for this study. In GARSH, five were tested positive only two volunteered for this study making 26 Healthcare workers that tested positive in all the three hospitals. 52controls were used for the study, making a ratio of 1:2. Therefore, 78 participants were involved in the study.

Among the positive HCWS, most were asymptomatic but werehospitalized. Only one was admitted to the intensive care unit. There were two deaths, an attendant and an auditor at Federal Medical Centre Katsina. No death case was recorded in the other treatment centre.

There were 63 males $(78.8 \%)$ and $15(21.2 \%)$ females in this study TABLE 1 :

\begin{tabular}{|c|c|c|c|c|c|}
\hline \multirow[b]{2}{*}{ Sex } & \multicolumn{4}{|c|}{ Status } & \multirow[b]{2}{*}{ Total } \\
\hline & Cases & $\%$ & Control & $\%$ & \\
\hline Male & 22 & 84.6 & 41 & 78.8 & 63 \\
\hline Female & 4 & 15.4 & 11 & 21.2 & 15 \\
\hline $\begin{array}{c}\text { prefer not to } \\
\text { answer }\end{array}$ & 0 & 0.0 & 0 & 0.0 & 0 \\
\hline Total & 26 & 100 & 52 & 100 & 78 \\
\hline
\end{tabular}

The mean age is 36.19 . Those with no education were 3(3.8\%). Those with secondary education were $6(7.7 \%)$ Those with tertiary education were 65(83\%). Respondents that were married were 51(65\%), while those that were single were $27(35 \%)$. No respondents were divorced or widowed. Many doctors participated in this study, 55(71\%), six registered nurses (8\%). Medical lab scientists were $3(4 \%)$, Cleaners $2(3 \%)$ Health attendants were $9(12 \%)$. Those tested for covid-19 were 26 (33\%). while those that did not were 52 (67\%).Table2 


\begin{tabular}{|c|c|c|c|c|}
\hline Variables & & Frequency $\mathrm{N}=78$ & Percen & $\%$ \\
\hline Mean age (SD), Min-Max & \multicolumn{3}{|c|}{$36.19(6.7), 24-53$} & \\
\hline \multirow[t]{4}{*}{ Highest educational qualification } & no education & 3 & 3.8 & \\
\hline & Primary & 4 & 5.1 & \\
\hline & secondary school & 6 & 7.7 & \\
\hline & Tertiary & 65 & 83 & \\
\hline \multirow[t]{5}{*}{ Marital status of the participants } & Single & 27 & 35 & \\
\hline & Married & 51 & 65 & \\
\hline & Divorced & 0 & 0 & \\
\hline & Separated & 0 & 0 & \\
\hline & Widowed & 0 & 0 & \\
\hline \multirow{9}{*}{$\begin{array}{l}\text { The department to the participant } \\
\text { belongs. }\end{array}$} & $\mathrm{A}$ and $\mathrm{E}$ & 8 & 10 & \\
\hline & medical wards & 0 & 0 & \\
\hline & surgical wards & 0 & 0 & \\
\hline & ICU & 7 & 9 & \\
\hline & isolation ward & 6 & 7.7 & \\
\hline & Admin & 0 & 0 & \\
\hline & Pediatrics wards & 2 & 2.6 & \\
\hline & $0 \& G$ & 9 & 12 & \\
\hline & Others & 46 & 59 & \\
\hline \multirow[t]{9}{*}{ Designation of the HCW } & Medical doctor & 55 & 71 & \\
\hline & physician assistant & 0 & 0 & \\
\hline & registered nurse & 6 & 7.7 & \\
\hline & Phlebotomist & 0 & 0 & \\
\hline & MLS & 3 & 3.8 & \\
\hline & Nutritionist & 0 & 0 & \\
\hline & Admin & 0 & 0 & \\
\hline & Cleaner & 2 & 2.6 & \\
\hline & Others & 12 & 15 & \\
\hline \multirow[t]{2}{*}{ Tested for COVID-19 } & Yes & 26 & 33 & \\
\hline & No & 52 & 67 & \\
\hline
\end{tabular}

Table 2: Sociodemographic Characteristics of the Study Participants

Departments in which HCWs were exposed to a confirmed case of covid-19 are as shown in the table below.

\begin{tabular}{|c|c|c|c|c|c|c|c|}
\hline \multicolumn{2}{|c|}{} & \multicolumn{9}{c|}{ Where Did the Contact Occur } \\
\cline { 3 - 8 } \multicolumn{2}{|c|}{} & & call duty & A $\$ \mathrm{E}$ & clinic & ward & others \\
\hline $\begin{array}{c}\text { Were you exposed to a confirmed case of } \\
\text { a COVID-19 patient? }\end{array}$ & yes & & 10 & 15 & 1 & 14 & 26 \\
\cline { 2 - 8 } & no & 12 & 0 & 0 & 0 & 0 & 0 \\
\hline $\begin{array}{c}\text { Did the patient have symptoms } \\
\text { suggestive of COVID-19 at first contact? }\end{array}$ & yes & & 6 & 9 & 0 & 9 & 19 \\
\cline { 2 - 9 } & no & 9 & 4 & 6 & 1 & 5 & 10 \\
\hline
\end{tabular}

Table 3: Exposure to a Confirmed Case of Covid-19

\begin{tabular}{|c|c|c|c|c|c|c|}
\hline & & & & \multicolumn{3}{|c|}{$\begin{array}{l}\text { Did you know what the risk } \\
\text { assessment for PPE use is? }\end{array}$} \\
\hline & & & & & Frequency & Per cent \\
\hline \multirow{3}{*}{$\begin{array}{l}\text { Were you adequately } \\
\text { trained to protect yourself } \\
\text { against SARS COV } 2 ?\end{array}$} & & Frequency & percentages & yes & 17 & 23.1 \\
\hline & yes & 37 & 47.436 & no & 61 & 76.9 \\
\hline & no & 41 & 52.564 & Total & 78 & 100.0 \\
\hline \multicolumn{7}{|c|}{ If yes, what is it? } \\
\hline \multirow{2}{*}{\multicolumn{5}{|c|}{ NO }} & \multicolumn{2}{|c|}{ Frequency } \\
\hline & & & & & \multicolumn{2}{|c|}{61} \\
\hline \multicolumn{5}{|c|}{ ABILITY TO TRIAGE THE PATIENT } & \multicolumn{2}{|c|}{1} \\
\hline \multicolumn{5}{|c|}{ APPROPRIATE PPE BASED ON RISK } & \multicolumn{2}{|c|}{1} \\
\hline \multicolumn{5}{|c|}{ APPROPRIATE USE OF PPE AND EVALUATION OF INFECTION } & \multicolumn{2}{|c|}{1} \\
\hline \multicolumn{5}{|c|}{ MEASURES TAKEN WHILE USING PPE } & \multicolumn{2}{|c|}{1} \\
\hline \multicolumn{5}{|c|}{ PROTECTIVE MEASURES } & \multicolumn{2}{|c|}{1} \\
\hline \multicolumn{5}{|c|}{ RISK OF CONTACTING INFECTION WHEN EXPOSED TO A PT } & \multicolumn{2}{|c|}{1} \\
\hline \multicolumn{5}{|c|}{ RISK OF EXPOSURE DURING REMOVING PPE } & \multicolumn{2}{|c|}{2} \\
\hline \multicolumn{5}{|c|}{ USE OF PPE } & \multicolumn{2}{|c|}{2} \\
\hline \multicolumn{5}{|c|}{ USING PPE TO PROTECT FROM INFECTION } & \multicolumn{2}{|c|}{1} \\
\hline \multicolumn{5}{|c|}{ Total } & \multicolumn{2}{|c|}{78} \\
\hline
\end{tabular}


Those that responded to the availability of facilities for hand hygiene were also included in the table.The majority of HCWs (73) did not have the premorbid condition. Those HCWS with hypertension were 2, hypertension and asthma were one, diabetes one, Asthma one. Those that adequately trained for SARS COV 2 were 37 (47\%). Those that were not were 41 (53\%). Those who knew what risk assessment was few 17 (23\%) while those that did not were 61 (77\%). Their view on what risk assessment is on the table below.

\begin{tabular}{|c|c|c|c|c|}
\hline If Yes to Premorbid Conditions & yes & no & & \\
\hline & 0 & 73 & & \\
\hline Nil & 2 & 0 & & \\
\hline Hypertension & 1 & 0 & & \\
\hline Hypertension, asthma & 1 & 0 & & \\
\hline Diabetes & 0 & 0 & & \\
\hline Heart disease & 0 & 0 & & \\
\hline Renal disease & 1 & 0 & & \\
\hline Asthma & 0 & 0 & & \\
\hline Others
\end{tabular}

Table 5: Premorbid Condition

\subsection{Community Exposure}

HCWS that have a history of staying in the same household with the confirmed patient were $47(60.3 \%)$ Those that did not were 31 (39.7\%) Those with a history of travelling with a confirmed case of covid-19 were $24(30.8 \%)$. Those without were 54(69.2\%). Table 6

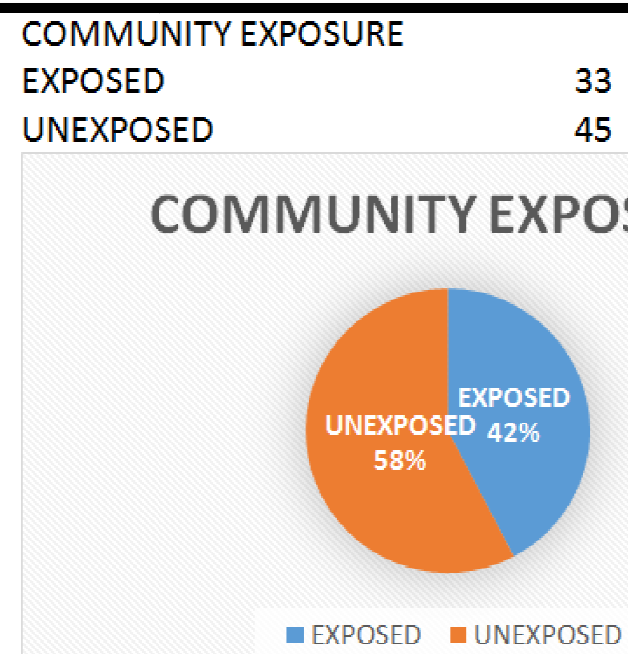

Figure 1

\begin{tabular}{|l|l|c|c|}
\hline \multicolumn{2}{|c|}{ Community Exposure } & Total & Percentage \\
\hline $\begin{array}{l}\text { Does the Healthcare Workers have a } \\
\text { history of staying in the same } \\
\text { household with a confirmed patient }\end{array}$ & Yes & 47 & $60.3 \%$ \\
\cline { 2 - 4 } & No & 31 & $39.7 \%$ \\
\hline & & 78 & $100.0 \%$ \\
\hline $\begin{array}{l}\text { Does the Healthcare Workers have a } \\
\text { history of travelling with the } \\
\text { confirmed case }\end{array}$ & Yes & 24 & $30.8 \%$ \\
\cline { 2 - 4 } & No & 54 & $69.2 \%$ \\
\hline
\end{tabular}

Table 6 


\begin{tabular}{|c|c|c|c|c|c|c|}
\hline \multirow{4}{*}{$\begin{array}{l}\text { Does the Healthcare } \\
\text { Workers have a } \\
\text { history of staying in } \\
\text { the same household } \\
\text { with a confirmed } \\
\text { patient }\end{array}$} & & \multicolumn{2}{|c|}{ Cases } & \multicolumn{2}{|c|}{ Control } & \multirow[t]{2}{*}{ TOTAL } \\
\hline & & Total & $(\%)$ & Total & $(\%)$ & \\
\hline & EXPOSED & 16 & 61.5 & 28 & 53.8 & 44 \\
\hline & UNEXPOSED & 10 & 38.5 & 24 & 46.2 & 34 \\
\hline & TOTAL & 26 & & 52 & & 78 \\
\hline *ODD RATIO & 1.4 & & & & & \\
\hline \multicolumn{7}{|c|}{$\begin{array}{l}\text { Those with covid-19 are } 1.4 \text { times as likely to have the exposure compared to those } \\
\text { without covid-19. }\end{array}$} \\
\hline \multirow{5}{*}{$\begin{array}{c}\text { Does the HCW have a } \\
\text { history of travelling } \\
\text { with the confirmed } \\
\text { case? }\end{array}$} & & \multicolumn{2}{|c|}{ Cases } & \multicolumn{2}{|c|}{ Control } & TOTAL \\
\hline & & Total & $(\%)$ & Total & $(\%)$ & \\
\hline & EXPOSED & 6 & 23.1 & 17 & 32.7 & 23 \\
\hline & UNEXPOSED & 20 & 76.9 & 35 & 67.3 & 55 \\
\hline & TOTAL & 26 & & 52 & & 78 \\
\hline *ODD RATIO & 0.6 & & & & & \\
\hline
\end{tabular}

Table 7: Community Exposure to Covid-19 Case and Control

\subsection{Occupational Exposure}

Health care workers with low risk of exposure were $64.1 \%$, while those with high risk were $35.9 \%$. These are shown in the table below.

\begin{tabular}{|l|r|}
\hline Occupational Exposure & \\
\hline LOW RISK & 64.1 \\
\hline HIGH RISK & 35.9 \\
\hline
\end{tabular}

Table 8

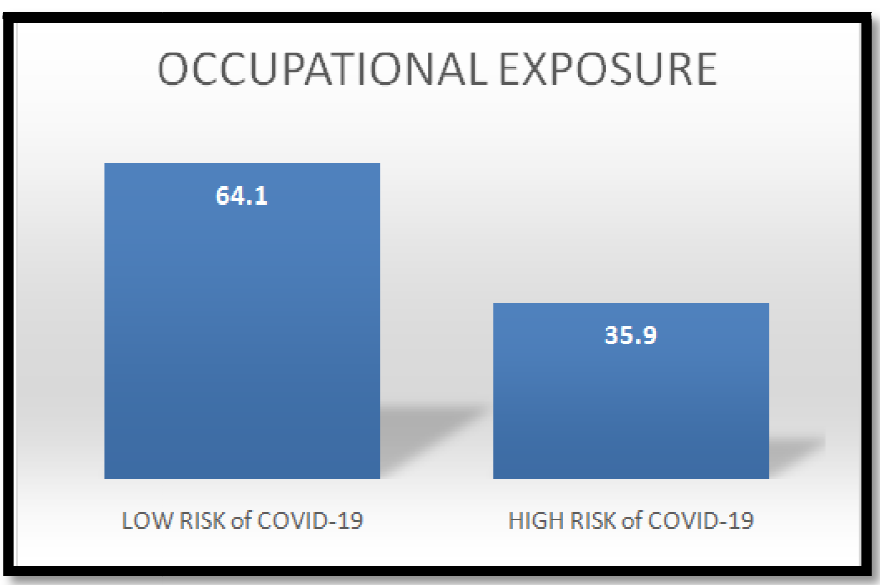

Figure 2

In Q4of the WHO risk assessment, those that provided direct care to a confirmedcovid-19 patient were53(67.90\%) while those that did not were $23(29.50 \%)$ and those that were not sure were $2(2.60 \%)$. Those with faceto-face contact within one meter were $66(84.60 \%)$, while those without contact were $10(12.80 \%)$, and those that were not sure were $2(2.60 \%)$. Those that were present during the aerosol-generating procedure performed on the patient were $27(34.60 \%)$. Those not present were $42(53.80 \%)$. Those that were not sure were $9(11.60 \%)$. Out of the 27 HCWs present for resuscitation, $7(8.90 \%)$ HCWs were present during cardiac resuscitation,6(7.70\%) HCWs were both presents for collection of sputum and open airway suctioning, while others were $2(2.6 \%)$. These are shown in the table below. The majority, $67(85.9 \%)$ of HCWs, directly contact the environment where confirmed cases have cared. Those that did not were $11(14.1 \%)$.Table9. 


\begin{tabular}{|c|c|c|}
\hline \multirow{4}{*}{$\begin{array}{l}\text { Did you provide direct care to a confirmed covid- } \\
19 \text { patient? }\end{array}$} & & \\
\hline & yes & 53 \\
\hline & no & 26 \\
\hline & unknown & 2 \\
\hline \multirow[t]{4}{*}{ Did you have face-to-face contact (within 1metre) } & & \\
\hline & yes & 66 \\
\hline & no & 10 \\
\hline & unknow & 2 \\
\hline \multirow{4}{*}{$\begin{array}{l}\text { Were you present when aerosol-generated } \\
\text { procedures were performed on the patient? }\end{array}$} & & \\
\hline & yes & 27 \\
\hline & no & 42 \\
\hline & unknown & 9 \\
\hline \multirow[t]{9}{*}{ If yes, what type of procedure? } & & 51 \\
\hline & $\begin{array}{l}\text { Tracheal } \\
\text { intubation }\end{array}$ & 5 \\
\hline & $\begin{array}{l}\text { Nebulizer } \\
\text { treatment }\end{array}$ & 1 \\
\hline & $\begin{array}{l}\text { Open airway } \\
\text { suctioning }\end{array}$ & 6 \\
\hline & $\begin{array}{l}\text { collection of } \\
\text { sputum }\end{array}$ & 6 \\
\hline & Tracheotomy & 0 \\
\hline & Bronchoscopy & 0 \\
\hline & $\begin{array}{l}\text { cardiopulmona } \\
\text { ry resuscitation }\end{array}$ & 7 \\
\hline & others & 2 \\
\hline \multirow{4}{*}{$\begin{array}{l}\text { Did you have direct contact with the environment } \\
\text { of the confirmed case? }\end{array}$} & & \\
\hline & yes & 67 \\
\hline & no & 11 \\
\hline & unknown & 0 \\
\hline \multirow{4}{*}{$\begin{array}{l}\text { Did you have direct contact with the environment } \\
\text { where the confirmed case has cared? }\end{array}$} & & \\
\hline & yes & 67 \\
\hline & no & 11 \\
\hline & unknown & 0 \\
\hline
\end{tabular}

Table 9: Health Care Workers Risk Assessment

The Q5 and Q 6 of the WHO risk assessment form are high risks and low risk of contractingcovid-19.Health Care Workers involved in health care interaction at other facility were $14(17.9 \%)$ home care $3(3.8 \%)$, ambulance $3(3.8 \%)$ those not involved and other health care facility were 52(66.7\%).The above results were HCW activities performed on the covid-19 patient in health care facility under the WHO risk assessment and management of exposure of health care workers interacting with the covid-19 patient. Results on adherence to IPC procedure during health care interactions include; HCW who wear PPE during health care interaction with covid-19 patients were 64 (82.1\%). Those who did not wear 7 (9\%). Those who wear gloves as always recommended were 43 (55.1\%), those who wear gloves most of the time were $18(23.1 \%)$ those who occasionally wear gloves were $2(2.6 \%)$. Those who use medical mask always as recommended were 45 (57.7\%) most of the time were $15(19.2 \%)$, occasionally 1 (1.3\%) rarely 2 (2.6\%). HCW who use disposable gown always as recommended were 17 (21.8\%), most of the time 7 (9\%) occasionally, 12 (15.4\%) rarely 28 (35.9\%). In adherence to IPC procedure during health care interactions always as recommended means over 95\% of the 
time, most of the time means $50 \%$ or more but not $100 \%$, occasionally means $20 \%$ to under $50 \%$ and rarely means less than $20 \%$.

Those HCW who removed and replaced PPE according to the protocol that is, when mask becomes wet, dispose of the wet PPE in the waste bin, perform hand hygiene always as recommended were 21 (26.9\%), most of the time 30 (38.5\%) occasionally3(3.8\%), rarely $11(14.1 \%)$. Those who performed hand hygiene before and after touching covid-19 patient always as recommended were 42 (53.8\%), most of the time 21 (26.9\%), occasionally 1 (1.3\%), rarely 1 (1.3\%). Those that performed hand hygiene before aseptic procedure always as recommended 42 (53.8\%), most of the time 16 (20.5\%), occasionally $1(1.3 \%)$ rarely $3(3.8 \%)$. HCW who perform hand hygiene before and after touching body fluids always as recommended were $51(65.4 \%)$ most of the time $8(10.3 \%)$ rarely $2(2.6 \%)$. Those who perform hand hygiene after touching the patients' surrounding always as recommended were 36 (46.2\%), most of the time 26 (33.3\%) occasionally $1 .(1.3 \%)$ rarely 2 (2.6\%). High surface decontamination at least three times daily, always as recommended were $20(25.6 \%)$ most of the time $21(26.9 \%)$ occasionally $18(23.1 \%)$ rarely $6(7.7 \%)$. The above section is adherence to IPC procedure during health care interaction to IPC measure when performing the aerosol-generating procedure, e.g. tracheal intubation, nebulizer treatment, HCW that wore PPES during aerosol-generating procedures were 45 (57.4\%) those that did not were $12(15.4 \%)$ those that wear gloves always as recommended were 37 (47.4\%) most of the time 7 $(9.0 \%)$, rare $1(1.3 \%)$ those that use N95 mask equivalent respiration always as recommended were 19 (24.4\%) most of the time $17(21.8 \%)$ occasionally $3(3.8 \%)$ rarely $5(6.4 \%)$. Those that use face shield or goggles protective glasses always as recommended were $12(15.4 \%)$, most of the time $13(16.7 \%)$ occasionally $6(7.7 \%)$ rarely $13(16.7 \%)$. The use of disposable gowns always as recommended were $14(17.9 \%)$, most of the time $11(14.1 \%)$ occasionally $6(7.7 \%)$ rarely 13 (16.7\%). Those who used waterproof gown always as recommended were $9(11.5 \%)$ most of the time, 9 (11.5\%), occasionally $12(15.4 \%)$ rarely $14(17.9 \%)$. Those who removed and replaced the PPE according to protocol always as recommended were 19 (24.4\%), most of the time 18 (23.1\%), occasionally 5 (6.4\%), rarely 3 (3.8\%). Respondents who performed hand hygiene before and after touching body fluids procedure always as recommended 30 (38.5\%), most of the time $12(15.4 \%)$ occasionally $3(3.8 \%)$, rarely $1(1.3 \%)$. HCW who performed hand hygiene before aseptic procedure always as recommended were $33(42.3 \%)$ most of the time $12(15.4 \%)$ occasionally 3 (3.8\%) rarely 1 (1.3\%). HCW who performed hand hygiene before aseptic procedure always as recommended were 33 (42.3\%), most of the time 12 (15.4\%) occasionally $1(1.3 \%)$. Those that performed hand hygiene always as recommended 30 (38.5\%), most of the time 16 $(20.5 \%)$ occasionally $1(1.3 \%)$ rarely $1(1.3 \%)$. HCW during aerosol generally procedures were high surface were decontaminated frequently, always as recommended were 14 (17.9\%), most of the time 22 (28.2\%), occasionally 9 (11.5\%) rarely $3(3.8 \%)$ TABLE10.

\begin{tabular}{|c|c|c|c|c|c|c|c|c|c|}
\hline \multirow{6}{*}{ 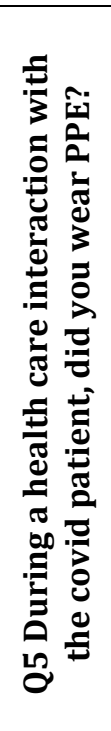 } & Yes & 70 & \multirow[b]{2}{*}{ 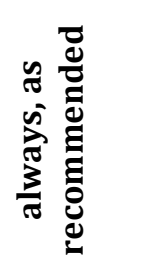 } & \multirow{2}{*}{$\begin{array}{l}\frac{1}{5} \\
3 \\
0 \\
0\end{array}$} & \multirow[b]{2}{*}{ 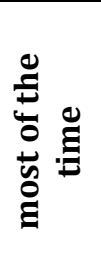 } & \multirow[b]{2}{*}{ 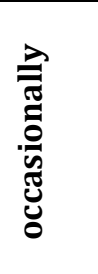 } & \multirow[b]{2}{*}{$\frac{\overrightarrow{0}}{\overrightarrow{0}}$} & \multirow[b]{2}{*}{ 焉 } & \multirow[b]{2}{*}{ 点 } \\
\hline & no & 8 & & & & & & & \\
\hline & $\begin{array}{l}\text { If yes to } \\
\text { single-use } \\
\text { gloves }\end{array}$ & & 56 & $\begin{array}{c}71.79 \\
487 \\
\end{array}$ & 20 & 2 & 0 & 22 & 28.20513 \\
\hline & $\begin{array}{l}\text { If yes to use f } \\
\text { a medical } \\
\text { mask. }\end{array}$ & & 53 & $\begin{array}{c}67.94 \\
872\end{array}$ & 22 & 1 & 2 & 25 & 32.05128 \\
\hline & $\begin{array}{l}\text { If yes, for the } \\
\text { face shield. }\end{array}$ & & 24 & $\begin{array}{c}30.76 \\
9\end{array}$ & 17 & 8 & 29 & 54 & 69.23077 \\
\hline & $\begin{array}{l}\text { If yes to use } \\
\text { of disposable } \\
\text { gown. }\end{array}$ & & 26 & $\begin{array}{c}33.33 \\
333 \\
\end{array}$ & 9 & 13 & 30 & 52 & 66.66667 \\
\hline $\begin{array}{l}\text { Did yo } \\
\text { PPE a }\end{array}$ & $\begin{array}{l}\text { ve and replace } \\
\text { g to protocol? }\end{array}$ & & 27 & $\begin{array}{c}34.61 \\
538\end{array}$ & 35 & 5 & 11 & 51 & 65.38462 \\
\hline & & & 51 & $\begin{array}{c}65.38 \\
462 \\
\end{array}$ & 25 & 1 & 1 & 27 & 34.61538 \\
\hline $\begin{array}{r}\text { Did } \\
\text { hygie }\end{array}$ & $\begin{array}{l}\text { rform hand } \\
\text { re the aseptic } \\
\text { dure? }\end{array}$ & & 51 & $\begin{array}{c}65.38 \\
462\end{array}$ & 23 & 1 & 3 & 27 & 34.61538 \\
\hline $\begin{array}{r}\text { Did } \\
\text { hygien } \\
\text { tou }\end{array}$ & $\begin{array}{l}\text { rform hand } \\
\text { e and after the } \\
\text { ody fluids } \\
\text { dure? }\end{array}$ & & 64 & $\begin{array}{c}82.05 \\
128 \\
\end{array}$ & 12 & 0 & 2 & 14 & 17.94872 \\
\hline $\begin{array}{r}\text { Did } \\
\text { hygie } \\
\text { patie }\end{array}$ & $\begin{array}{l}\text { rform hand } \\
\text { touching the } \\
\text { rroundings? }\end{array}$ & & 46 & $\begin{array}{c}58.97 \\
436 \\
\end{array}$ & 29 & 1 & 2 & 32 & 41.02564 \\
\hline
\end{tabular}




\begin{tabular}{|c|c|c|c|c|c|c|c|c|c|}
\hline \multicolumn{2}{|c|}{$\begin{array}{c}\text { Were high surfaces } \\
\text { decontaminated frequently }\end{array}$} & & \multirow[t]{2}{*}{28} & \multirow[t]{2}{*}{$\begin{array}{c}35.89 \\
744\end{array}$} & \multirow[t]{2}{*}{26} & \multirow[t]{2}{*}{18} & \multirow[t]{2}{*}{6} & \multirow[t]{2}{*}{50} & \multirow[t]{2}{*}{64.10256} \\
\hline \multirow{7}{*}{ 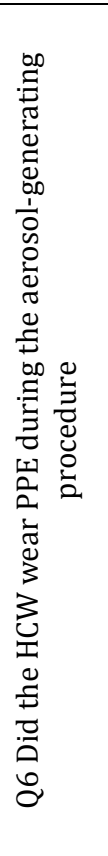 } & Yes & 62 & & & & & & & \\
\hline & No & 16 & & & & & & & \\
\hline & $\begin{array}{l}\text { Single-use } \\
\text { gloves }\end{array}$ & & 62 & $\begin{array}{c}79.48 \\
718\end{array}$ & 15 & 0 & 1 & 16 & 20.51282 \\
\hline & $\begin{array}{l}\text { use of N95 or } \\
\text { equivalent } \\
\text { respirator }\end{array}$ & & 24 & $\begin{array}{c}30.76 \\
923\end{array}$ & 39 & 10 & 5 & 54 & 69.23077 \\
\hline & $\begin{array}{l}\text { Use of face } \\
\text { shield or } \\
\text { goggles or } \\
\text { protective } \\
\text { glasses }\end{array}$ & & 33 & $\begin{array}{c}42.30 \\
769 \\
\end{array}$ & 25 & 6 & 14 & 45 & 57.69231 \\
\hline & $\begin{array}{l}\text { Use of } \\
\text { disposable } \\
\text { gown }\end{array}$ & & 32 & $\begin{array}{c}41.02 \\
564\end{array}$ & 26 & 6 & 14 & 46 & 58.97436 \\
\hline & $\begin{array}{l}\text { Use of } \\
\text { waterproof } \\
\text { gown }\end{array}$ & & 10 & $\begin{array}{c}12.82 \\
051\end{array}$ & 9 & 25 & 34 & 68 & 87.17949 \\
\hline \multicolumn{2}{|c|}{$\begin{array}{c}\text { Did you remove and replace } \\
\text { your PPE according to } \\
\text { protocol? }\end{array}$} & & 23 & $\begin{array}{c}29.48 \\
718 \\
\end{array}$ & 26 & 12 & 17 & 55 & 70.51282 \\
\hline \multicolumn{2}{|c|}{$\begin{array}{l}\text { Did you perform hand } \\
\text { hygiene before and after the } \\
\text { touching body fluids } \\
\text { procedure? }\end{array}$} & & 43 & $\begin{array}{c}55.12 \\
821\end{array}$ & 24 & 9 & 2 & 35 & 44.87179 \\
\hline \multicolumn{2}{|c|}{$\begin{array}{c}\text { Did you perform hand } \\
\text { hygiene before the aseptic } \\
\text { procedure? }\end{array}$} & & 35 & $\begin{array}{c}44.87 \\
179\end{array}$ & 25 & 15 & 3 & 43 & 55.12821 \\
\hline \multicolumn{2}{|c|}{$\begin{array}{l}\text { Did you perform hand } \\
\text { hygiene after touching the } \\
\text { patient's surroundings? }\end{array}$} & & 33 & $\begin{array}{c}42.30 \\
769 \\
\end{array}$ & 34 & 9 & 2 & 45 & 57.69231 \\
\hline \multicolumn{2}{|c|}{$\begin{array}{c}\text { Were high surfaces } \\
\text { decontaminated frequently }\end{array}$} & & 20 & $\begin{array}{c}25.64 \\
103\end{array}$ & 35 & 17 & 6 & 58 & 74.35897 \\
\hline
\end{tabular}

Section 7 Accident with Biological Material

Health Care Workers who had accident with body fluids or respiratory secretions were 2 (2.6\%), those who did not were 74 (94.9\%) out of the two HCWs that had accident with body fluids or respiratory secretions 1 (1.3\%) had a splash of biological fluids/respiration secretions eye. The other had a splash of biological fluids respiration secretions to intact skin 1 (1.3\%). TABLE11.

\begin{tabular}{|c|c|c|}
\hline \multicolumn{3}{|c|}{$\begin{array}{l}\text { Did you have an accident with body } \\
\text { fluids or respiratory secretions? }\end{array}$} \\
\hline & Frequency & Per cent \\
\hline Yes & 2 & 2.6 \\
\hline No & 76 & 97.4 \\
\hline Total & 78 & 100.0 \\
\hline
\end{tabular}

The various units where exposure occurred were those that have direct care to a confirmed covid-19 patient were $53(67,9 \%)$, those that did not were $21(26.9 \%)$, and those that are not sure were $12(2.6 \%)$ those that had face to face contact (within) with a confirmed covid-19 patient in a health care facility were $66(84.6 \%)$, those that did not were 7 $(9 \%)$ and those that were not sure are $2(2.6 \%)$ 
Those HCW present when any aerosol generated procedures were performed on the patient were 26 (33.3\%), those not present were 41 (52.6\%), those not sure were $9(11.5 \%)$. Out of the 23 HCWs, present during an aerosolgenerating procedure like tracheal incubation $5(6.4 \%)$ cardiopulmonary resuscitation 7 (9.9\%) collection of sputum 6 (7.7\%) open airway suctioning $5(6.4 \%)$ nebulizer treatment $1(1.3 \%)$

The majority, $66(84.6 \%)$, had direct contact with the environment where confirmed covid-19 cases were cared for while 9 (11.5\%), did not directly contact patient's environment in terms of bed linen, medical equipment, bathroom etc.

Questions 5 and 6 deals with high and low-risk group. During a health care interaction with the covid patient, was PPE worn by Health care workers. Those who wore single used gloves were $56(72 \%)$ low risk and high risk of $22(28 \%)$. Those who wore face mask always recommended were 53(68\%), low risk while those with high risk were 25(32\%). HCWs who continuously remove their face shield as recommended were $24(31 \%)$, low risk while the high risk was $54(69 \%)$. Those who consistently use disposable gowns were 26(33\%) low risk, while those with high risk were 54(67\%). Can see other parameters in the table below. For question 6, addressed adherence to IPC procedures to HCWs who did not respond 'yes to always as recommended' for Q6A-6F were categorized as a high- risk group. The same goes for 7A. Those HCWS who wore PPEs during aerosol-generating procedures were 62, while those that did not were 16 . Those that wore single used gloves were $62(79 \%)$ low risk, while those with high risk were $16(21 \%)$. Those who wore N95 or equivalent respirator were $24(31 \%$ low risk while those that were high risk were (54\%). Use of face shield, goggles or protective glasses were 33(415) low-risk ad 46(59\%) high risk. Those who consistently remove and replace PPE according to the protocol were 23(29\%) low risk and 55(71\%) high risk,HCWs who performed hand hygiene before and after touching covid-19 patients were 43 (55\%) low risk and 35 (45\%) high risk. Those that performed hand hygiene before and after any clean or aseptic procedure was performed were 35(45\%) low risk, and $43(55 \%)$ high risk. Those that performed hand hygiene after touching covid-19 patient surroundings were 33(42\%) low risk and 45 (58\%) highrisk. Decontamination of high surfaces at least three times daily were $20(26 \%)$ low risk and $58(74 \%)$ high risk. Question 7 of WHO assessment.Those with biological material accidents were 2(2.6\%) and 76(97.4\%) without accident.

Comparing community exposure rate of positive HCWS to those negativecontrol. There were 16(61.5\%) HCWs with a history of staying in the same household witha confirmed covid-19 case. Their control counterpart was $28(53.8 \%)$, while those that were unexposed were $10(38.5 \%)$. The control counterpart was $24(46.2 \%)$ TABLE 7 . Hence, those with covid-19 are 1.4 times more likely to have exposure than those without covid-19. Positive HCWs with a history of exposure to travelling with confirmed covid-19 cases were 6(23.1\%) The control HCWs were $17(32.7 \%)$. Positive HCWs unexposed were $20(76.9 \%)$ while the control counterpart was 35 (67.3\%). Those positive HCWs with Covid-19 are 0.6 times likely to have exposure than those that are not. Question 6 of the WHO risk assessment also compared the positive cases to the control. The positive cases with high risk include, Use of N95 (73\%) or equivalent, use of face shield or Goggles (54\%), use of the disposable gown (54\%), use of waterproof gown (88\%). Removing and replacing PPE according to the protocol(85\%) Performing hand hygiene before and after touching body fluids procedure(50\%), Performing hand hygiene before aseptic procedures(62\%). Performing hand hygiene after touching the patient's surroundings (77\%).Frequent high surface decontamination(81\%).Comparing the high risk above to that of the control are N95(67\%) Face shield or goggles(60\%), disposable gown (62\%), Waterproof gown $(87 \%)$, removing and replacing PPE according to the protocol(63\%), hand hygiene before and after touching body fluid procedures(42\%) low risk in the positive case was $(13 \%)$. In comparison, that of control was (58\%)Furthermore, High risk in the case when performing hand hygiene before the aseptic procedure (62\%). At the same time, the control was (52\%) High risk in the case when performing hand hygiene after touching the patient's surroundings was (77\%) while control was (48\%). High risk infrequent high surfaces decontamination (81\%) while that of control was (52\%).

\begin{tabular}{|c|c|c|c|c|c|c|c|}
\hline \multirow{2}{*}{ Variables } & & \multicolumn{2}{|c|}{ Cases } & \multicolumn{2}{|c|}{ Control } & \multirow[t]{2}{*}{ Total } & \multirow[t]{2}{*}{ Percent } \\
\hline & & TOTAL & PERCENT & TOTAL & PERCENT & & \\
\hline \multirow{2}{*}{$\begin{array}{c}\text { During a health care } \\
\text { interaction with the COVID } \\
\text { patient, did you wear PPE? }\end{array}$} & low risk & 24 & 31 & 46 & 59 & 70 & 90 \\
\hline & High risk & 2 & 3 & 6 & 8 & 8 & 10 \\
\hline \multirow[t]{2}{*}{ If yes to single-use gloves } & low risk & 18 & 23 & 38 & 49 & 56 & 72 \\
\hline & High risk & 8 & 10 & 14 & 18 & 22 & 28 \\
\hline \multirow[t]{2}{*}{ If yes to use of medical mask } & low risk & 15 & 19 & 38 & 49 & 53 & 68 \\
\hline & High risk & 11 & 14 & 14 & 18 & 25 & 32 \\
\hline \multirow{2}{*}{$\begin{array}{l}\text { if yes for face shield or } \\
\text { goggles }\end{array}$} & low risk & 8 & 10 & 16 & 21 & 24 & 31 \\
\hline & High risk & 18 & 23 & 36 & 46 & 54 & 69 \\
\hline \multirow{2}{*}{$\begin{array}{l}\text { If yes to use of disposable } \\
\text { gown }\end{array}$} & low risk & 8 & 10 & 18 & 23 & 26 & 33 \\
\hline & High risk & 18 & 23 & 34 & 44 & 52 & 67 \\
\hline \multirow{2}{*}{$\begin{array}{l}\text { Did you remove and replace } \\
\text { PPE according to protocol }\end{array}$} & low risk & 10 & 13 & 16 & 21 & 26 & 33 \\
\hline & High risk & 16 & 21 & 36 & 46 & 52 & 67 \\
\hline Did you perform hand & low risk & 14 & 18 & 37 & 47 & 51 & 65 \\
\hline
\end{tabular}




\begin{tabular}{|c|c|c|c|c|c|c|c|}
\hline $\begin{array}{l}\text { hygiene before and after } \\
\text { touching the }\end{array}$ & High risk & 12 & 15 & 15 & 19 & 27 & 35 \\
\hline \multirow{2}{*}{$\begin{array}{c}\text { Did you perform hand } \\
\text { hygiene before the aseptic } \\
\text { procedure }\end{array}$} & low risk & 13 & 17 & 38 & 49 & 51 & 65 \\
\hline & High risk & 13 & 17 & 14 & 18 & 27 & 35 \\
\hline \multirow{3}{*}{$\begin{array}{l}\text { Did you perform hand } \\
\text { hygiene before and after the } \\
\text { touching body fluids } \\
\text { procedure? }\end{array}$} & & & & & & & 0 \\
\hline & low risk & 18 & 23 & 46 & 59 & 64 & 82 \\
\hline & High risk & 8 & 10 & 6 & 8 & 14 & 18 \\
\hline \multirow{2}{*}{$\begin{array}{l}\text { Did you perform hand } \\
\text { hygiene after touching the } \\
\text { patient's surroundings }\end{array}$} & low risk & 11 & 14 & 35 & 45 & 46 & 59 \\
\hline & High risk & 15 & 19 & 17 & 22 & 32 & 41 \\
\hline \multirow{2}{*}{$\begin{array}{c}\text { Were high surfaces } \\
\text { decontaminated frequently }\end{array}$} & low risk & 9 & 12 & 19 & 24 & 28 & 36 \\
\hline & High risk & 17 & 22 & 33 & 42 & 50 & 64 \\
\hline
\end{tabular}

Table 12: Healthcare Workers with Low and High-Risk Exposure to Covid-19 Case and Control

\subsection{Focal Group Discussion}

The Focal Group Discussion was held at Federal Medical Centre Katsina. There were 6 Participants A doctor representing each treatment centre, the principal investigator, a hospital attendant, a nurse who was the timekeeper. The Discussion lasted 65minutes. Each representative was made to answer some questions. In GARSH, no IPC team or committee in the hospital. There was no training on IPC on Covid-19before being posted to the isolation unit. No PPEs were provided by the hospital, Patients were made to provide Hand gloves before they are being attended to. Health care workers had to demonstrate before they were provided with face mask by the management, No googles or gowns were provided.

Hand washing facilities are available only on the wards, none in the clinics.PPEs such as mand gloves, facemask, goggles were not worn all the time; the representative from GARSH claimed to wash hands after and not before seeing patients. He also said he uses hand sanitizers after touching the patient's environment. He said he has never encountered any accident with confirmed covid-19 body fluid or respiratory secretions. He said the reason healthcare workers are coming down with the infection is a system failure. The 5000-naira hazard allowance being paid to workers across the board cannot buy hand gloves and face mask packets to talk of other PPEs. He also mentioned that the resuscitation equipment was not available; only two ventilators available in the whole of the hospital with no oxygen concentrator. The consultant made the junior Medical officers see patient making them vulnerable to Covid-19 infection.

Turai had an IPC committee; they were trained on IPC on Covid-19 by the Primary Health Care Agency and NCDC. But most doctors were not present during the training. He said PPEs were provided but not regularly. He also added that most of the PPEs were gotten from donations. He suggested that training and retraining of Health Care Workers would go a long way to curb infection among Health Care Workers.

FMC Katsina representative said there is a non-functional IPC team/Committee, he said no former training was given to those at the isolation centre, but they go by NCDC guidelines. PPEs were provided but not always. Hand washing facilities are available on both wards and clinics. He said HCWs are coming down with the infection because of improper training, carefree attitude and fire brigade approached.

Suggestion for curbing covid-19 were same as above.

\section{Discussion}

The community exposure of health care workers in this study is $60.3 \%$. The occupational exposure is $35.5 \%$. Community exposure is high compared to a study done in Ghanaxi. This is expected since the sites are designated treatment centres for covid-19. This study recorded more community exposure than occupational exposure; the reverse is the case with the study done in Ghana and United States ${ }^{11, x i i, ~ H e n c e, ~ h e a l t h ~ c a r e ~ w o r k e r s ~ a r e ~ a t ~ h i g h ~ r i s k ~ o f ~ e x p o s u r e ~ t o ~}$ covid-19. Regular training on IPC protocols with a steady supply of PPEs is the way forward.

Adherence to IPC procedure during interaction with Covid-19 patient is low even though the management of Federal

Medical Centre Katsina and non-governmental organisations donations made efforts to make PPEs available, but some do not use it consistently. Can see this in the findings on the high-risk groups: Those that did not use disposable gown were 67\%; those who did not remove their face shield as recommended 69\%; Those who did not wear N95 or its equivalent during aerosol-generating procedure 54\%; those who did not perform hand hygiene before and after any clean or aseptic procedure 55\%; Infrequent decontamination of high surfaces 74\%.The above findings require strict adherence to PPE use and infection control irrespectiveof whether the patient is Covid-19 positive or not. The management of Federal Medical Centre Katsina and non -governmental agencies should not relent in their effort on regular supplies of PPEs. Hence, it is imperative to reduce infection among healthcare workers. Health Care workers should endeavour to carry out the covid-19 test enabling one to know the actual number of those infected and prevent asymptomatic spread. Early covid19 detection among healthcare workers (HCWs) is crucial for protecting patients and healthcare workers.

Strict Use of PPE must be stressed to healthcare workers in all settings maintaining sufficient PPEs supplies and ensuring that everyone is effectively trained in infection, prevention and control to avoid risking their health. 
In the Focus group discussion held, most said, 'In the early pandemic PPEs were scarce, made some reuse PPE or forgo protection'. Hence, maintaining sufficient PPEs and ensuring that everyone is effectively trained in infection, prevention and control to avoid risking their health is the key.

Significant factors for covid-19 infection among HCWs are lack of understanding of covid-19 infection, inadequate Use and unavailability of PPEs, protection of HCWs by authorities should be prioritized through education and regular training, incentives, availability of PPEs and psychological support.

\section{Conclusion and Recommendation}

Those adequately trained for COVID were 37(47\%), not up to 50\%. Those that knew what risk assessment was were very few 17(23\%) HCWs with community exposure were 60.3\%. Those with occupational exposure were 35.9\%. High-risk groups involved in this study were the removal of face mask 54\%, Use of N95 or equivalent respirator 54\%, removal of PPE according to protocol 71\%, Hand hygiene after touching patients surrounding 58\%. Decontamination of high surfaces $74 \%$. Inadequately clean and sanitized surfaces compromised the disinfection of medical equipment. Hence, decontamination of high surfaces should be carried out at least three times a day. The health regulatory bodies should start with training and educating medical and supporting staff through compulsory online courses. Regular training on IPC protocols, constant supply of PPEs, monitoring HCWs on IPC practices and supervision, giving HCWs incentives as when due would go a long way in reducing the risk of covid-19 among HCWs.

\section{References}

i. ${ }^{1}$ Available at https://www.aa.com accessed at $2^{\text {nd }}$ June 2020, and punch newspapers available at healthwise.punch.ng.com accessed on $5^{\text {th }}$ July 2020

ii. $\quad{ }^{1}$ Available at https://www.who.int assessed on $2^{\text {nd }}$ June 2020

iii. ${ }^{1} \mathrm{R}$ Van Doremalin, $\mathrm{N}$ Bush Maker, T Morris DH et al 'Aerosol and surface stability of SARS-COV-2 as compared with SARS-COV-19 N Eng J Med 2020; 382:1564

iv. 4. Long H Nguyen, MD David A Drew, PhD Mark S Graham, PhD et al; 'Risk of COVID-19 among front-line healthcare workers and the general community: a prospective cohort study'

v. ${ }^{1}$ Available at https://www.ncdc.gov.ng>news $>$ nigeria-launches-covid-19

vi. ${ }^{1}$ Phan LT, Maita D, Mortiz DC, Weber R, Fritzen-Pedicini C, Bleasdale SC, et al. Personal protective equipment doffing practices of healthcare workers. J Occup Environ Hyg. 2019;16(8):575-81

vii. ${ }^{1}$ Over 10,000 health workers infected with COVID-19 in.... https://www.gsdmagazine.org/over-10000-healthworkers-infected-with-covid-19-in-africa-says-who/

viii. ${ }^{1}$ Infection and mortality of healthcare workers worldwide.... https://gh.bmj.com/content/bmjgh/5/12/e003097.full.pdf

ix. 1Verbeek JH, Rajamaki B, Ijaz S, et al. 'Personal protective equipment for preventing highly infectious diseases due to exposure to contaminated body fluids in healthcare staff'Cochrane Database Syst Rev. 2020; 4CD011621

x. $\quad{ }^{1}$ Risk assessment and management of exposure of health care.... https://apps.who.int/iris/bitstream/handle/10665/331496/WHO-2019-nCov-HCW_risk_assessment-2020.2eng.pdf

xi. ${ }^{1}$ Mary EyramAshinyo, Stephen DajaanDubik, Vida Duti et al; 'Healthcare workers exposure risk assessment: A survey among frontline workers in Designated Covid-19 treatment centers in Ghana' Journal of Primary Care and Community Health Volume 11: 1 - 10.DOI: 10.1177/2150132720969483

xii. ${ }^{1}$ COVID TC. Characteristics of health care personnel with COVID-19 United States, February 12 - April 9, 2020 , MMWR Morb Mortal Wkly Rep. 2020;69:477-481 